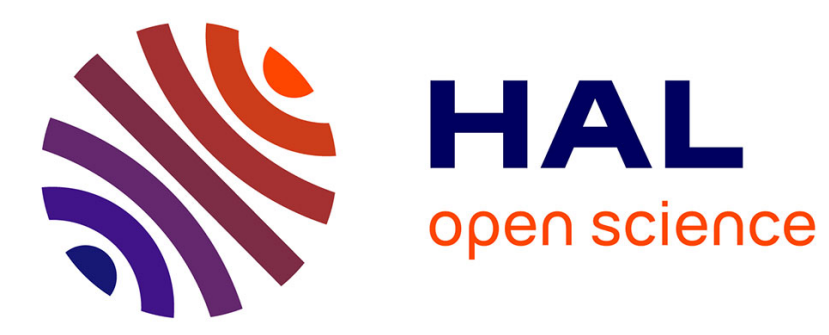

\title{
Orbital elements of six visual binary stars
}

\author{
Marco Scardia, Jean-Louis Prieur, Laurent Koechlin, Eric Aristidi
}

\section{To cite this version:}

Marco Scardia, Jean-Louis Prieur, Laurent Koechlin, Eric Aristidi. Orbital elements of six visual binary stars. Astronomical Notes / Astronomische Nachrichten, 2001, 322, pp.161. hal-02360275

\section{HAL Id: hal-02360275 \\ https://hal.science/hal-02360275}

Submitted on 12 Nov 2019

HAL is a multi-disciplinary open access archive for the deposit and dissemination of scientific research documents, whether they are published or not. The documents may come from teaching and research institutions in France or abroad, or from public or private research centers.
L'archive ouverte pluridisciplinaire HAL, est destinée au dépôt et à la diffusion de documents scientifiques de niveau recherche, publiés ou non, émanant des établissements d'enseignement et de recherche français ou étrangers, des laboratoires publics ou privés. 


\title{
Orbital elements of six visual binary stars
}

\author{
M. SCARDiA, Merate, Italy \\ Osservatorio Astronomico di Brera \\ J.-L. Prieur and L. Koechlin, Toulouse, France \\ Observatoire Midi-Pyrénées - Centre National de la Recherche Scientifique \\ E. Aristidi, Nice, France \\ Université de Nice Sophia-Antipolis - Centre National de la Recherche Scientifique
}

Received 2001 May 19; accepted 2001 June 26

Revised orbital elements of the visual binary stars STT 515, BU 4 AB, STF 183 AB, A 207, STT 43 and A 2413 are given. Dynamical parallaxes and total masses of the systems have been calculated.

Key words: visual binaries: orbits - stellar masses - dynamical parallaxes

\section{Introduction}

The present work is a continuation of the revision of some orbits of visual binary stars (Aristidi et al. 1999, Scardia et al. $2000 \mathrm{a}$ ), which are no longer valid, using the speckle observations obtained by the PISCO speckle camera developed by Observatoire Midi-Pyrénées and used on the Cassegrain focus of the 2-meter Télescope Bernard Lyot (TBL) of the Pic du Midi Observatory (Aristidi et al. 1997, Aristidi et al. 1999, Scardia et al. 2000 b). The procedures used for the revision of the orbital elements, the calculation of the sum of the masses of the system, and respective uncertainty, and the graphic representation of the results are the same as in the previous work (Scardia et al. 2000a). The values of the stellar masses as a function of the spectral type, used as reference, have been taken from Straizys and Kuriliene (1981). In the tables containing the ephemerides column 1 contains the date in years, column 2 the separation $\rho$ in arcsec and column 3 the position angle $\theta$ in degrees. In the tables of the O-C, restricted for reasons of space to the observations following 1978, column 1 contains the date in years, column 2 the observed separation $\rho$ in arcsec, column 3 the $\Delta \rho(O-C$ ), column 4 the observed position angle $\theta$ (reduced to 2000) in degrees, column 5 the $\Delta \theta(O-C)$, column 6 the number of nights and column 7 the name of the observer. The figures show the apparent orbit obtained by us and the observations used for the calculation of the orbital elements. The orientation of the orbit is in conformity with the convention accepted by the observers of visual binary stars.

\section{WDS $01095+4715$ - STT 515 - ADS 940}

The binary star has been well observed. The observations are quite numerous, but very scattered before 1940 when, because of the narrow separation and the strong brightness of the principal star, the couple was difficult to observe. The previous orbit of Baize (1958), although still acceptable in position angle, shows systematic residuals in separation. Thus we have recalculated the orbital elements obtaining:

\begin{tabular}{|c|c|c|c|}
\hline node & $=$ & 142.3 & $(2000)$ \\
\hline omega & $=$ & 249.0 & \\
\hline i & $=$ & 148.0 & $A=-0.09028$ \\
\hline e & $=$ & 0.258 & $B=-0.38062$ \\
\hline $\mathrm{T}$ & $=$ & 1886.926 & $F=-0.41605$ \\
\hline $\mathrm{P}$ & $=$ & 391.0 & $G=0.14864$ \\
\hline $\mathrm{n}$ & $=$ & 0.92072 & \\
\hline a & $=$ & 0.450 & \\
\hline
\end{tabular}


This orbit is preliminary. The real period is probably long ( $\mathrm{P}>400$ years), but for the moment it is, like the other orbital elements, still uncertain (Fig. 1). The parallax measured by the satellite Hipparcos is 0 ". $00443 \pm$ 0".00080. The sum of the masses of the system, corresponding to such a measurement, is $6.9 M_{\odot}$, slightly in excess for a binary of a spectral type B7Ve, while the semi-major axis is 101.6 A.U.. The dynamical parallax is 0".0033, in reasonable agreement with the measured one; but this calculated parallax is not acceptable because it leads to an exaggerated sum $\left(16.8 M_{\odot}\right)$ of the masses of the system.

Ephemerides

\begin{tabular}{|c|c|c|c|c|c|c|c|c|c|c|c|c|c|}
\hline 1 & 2 & 3 & & 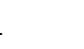 & 2 & 3 & & & & & & & \\
\hline 2001.0 & 0.497 & 125.6 & 200 & 3.0 & 0.501 & 122.5 & & & & & & & \\
\hline 2002.0 & 0.498 & 124.9 & 200 & 7.0 & 0.501 & 121.9 & & & & & & & \\
\hline 2003.0 & 0.498 & 124.3 & 200 & 3.0 & 0.502 & 121.3 & & & & & & & \\
\hline 2004.0 & 0.499 & 123.7 & 200 & 9.0 & 0.503 & 120.7 & & & & & & & \\
\hline 2005.0 & 0.500 & 123.1 & 201 & .0 & 0.503 & 120.1 & & & & & & & \\
\hline $0-C$ & & & & & & & $0-C$ & & & & & & \\
\hline 1 & 2 & 3 & 4 & 5 & 6 & 7 & 1 & 2 & 3 & 4 & 5 & 6 & 7 \\
\hline 1978.615 & 0.469 & 0.001 & 140.2 & -0.0 & 1 & MCA & 1988.655 & 0.490 & 0.007 & 132.7 & -0.7 & 1 & MCA \\
\hline 1978.770 & 0.490 & 0.022 & 140.6 & 0.5 & 3 & HEI & 1988.814 & 0.490 & 0.007 & 134.6 & 1.3 & 3 & WOR \\
\hline 1978.810 & 0.560 & 0.092 & 139.5 & -0.6 & 1 & POP & 1988.909 & 0.488 & 0.005 & 132.6 & -0.6 & 1 & $\mathrm{FU}$ \\
\hline 1979.732 & 0.490 & 0.020 & 141.6 & 2.1 & 1 & TOK & 1990.772 & 0.477 & -0.009 & 131.0 & -1.0 & 1 & BAG \\
\hline 1979.770 & 0.474 & 0.004 & 139.7 & 0.3 & 1 & MCA & 1990.835 & 0.480 & -0.006 & 132.4 & 0.4 & 1 & WSI \\
\hline 1979.874 & 0.460 & -0.010 & 141.0 & 1.7 & 3 & WOR & 1990.915 & 0.480 & -0.006 & 131.7 & -0.2 & 1 & WSI \\
\hline 1980.718 & 0.480 & 0.008 & 137.8 & -0.9 & 1 & MCA & 1990.942 & 0.470 & -0.016 & 130.0 & -1.9 & 1 & WSI \\
\hline 1980.882 & 0.479 & 0.007 & 139.0 & 0.4 & 1 & MCA & 1991.029 & 0.487 & 0.001 & 132.0 & 0.2 & 1 & BAG \\
\hline 1980.893 & 0.461 & -0.011 & 137.7 & -0.9 & 1 & MCA & 1991.250 & 0.491 & 0.005 & 131.3 & -0.4 & 1 & HIP \\
\hline 1980.898 & 0.483 & 0.011 & 137.8 & -0.8 & 1 & MCA & 1991.904 & 0.492 & 0.005 & 131.1 & -0.2 & 1 & MCA \\
\hline 1980.916 & 0.529 & 0.057 & 136.0 & -2.6 & 2 & TOK & 1992.678 & 0.474 & -0.014 & 132.0 & 1.2 & 1 & BAG \\
\hline 1981.701 & 0.476 & 0.003 & 138.1 & 0.1 & 1 & MCA & 1992.766 & 0.500 & 0.012 & 131.8 & 1.1 & 1 & WSI \\
\hline 1982.603 & 0.465 & -0.010 & 134.1 & -3.3 & 1 & TOK & 1992.766 & 0.490 & 0.002 & 133.6 & 2.9 & 1 & WSI \\
\hline 1982.670 & 0.460 & -0.015 & 138.7 & 1.3 & 2 & LEF & 1993.760 & 0.514 & 0.025 & 130.0 & -0.1 & 1 & BAG \\
\hline 1983.069 & 0.481 & 0.006 & 136.7 & -0.4 & 1 & MCA & 1993.762 & 0.507 & 0.018 & 131.0 & 0.9 & 1 & BAG \\
\hline 1983.716 & 0.479 & 0.003 & 136.6 & -0.1 & 1 & $\mathrm{MCA}$ & 1993.894 & 0.470 & -0.020 & 131.2 & 1.2 & 1 & WSI \\
\hline 1983.933 & 0.638 & 0.161 & 144.5 & 8.0 & 1 & $\mathrm{BNU}$ & 1993.920 & 0.490 & 0.000 & 130.2 & 0.2 & 1 & HRT \\
\hline 1984.060 & 0.478 & 0.001 & 136.7 & 0.3 & 1 & MCA & 1994.920 & 0.460 & -0.031 & 130.3 & 0.9 & 1 & WSI \\
\hline 1984.770 & 0.530 & 0.052 & 135.0 & -0.9 & 3 & HEI & 1994.986 & 0.470 & -0.021 & 128.7 & -0.6 & 1 & WSI \\
\hline 1984.997 & 0.482 & 0.004 & 135.5 & -0.3 & 1 & $\mathrm{MCA}$ & 1994.986 & 0.460 & -0.031 & 128.7 & -0.6 & 1 & WSI \\
\hline 1985.480 & 0.460 & -0.019 & 137.8 & 2.3 & 2 & WOR & 1995.760 & 0.492 & 0.000 & 129.0 & 0.2 & 1 & HRT \\
\hline 1985.753 & 0.492 & 0.013 & 135.9 & 0.6 & 2 & TOK & 1995.929 & 0.492 & 0.000 & 128.6 & -0.1 & 1 & HRT \\
\hline 1985.838 & 0.508 & 0.029 & 135.0 & -0.2 & 1 & $\mathrm{BNU}$ & 1996.052 & 0.490 & -0.002 & 128.2 & -0.5 & 1 & GII \\
\hline 1985.848 & 0.483 & 0.004 & 134.4 & -0.8 & 1 & MCA & 1996.927 & 0.470 & -0.023 & 129.1 & 1.0 & 1 & WSI \\
\hline 1986.883 & 0.500 & 0.019 & 134.3 & -0.2 & 4 & WOR & 1996.927 & 0.460 & -0.033 & 130.4 & 2.3 & 1 & WSI \\
\hline 1986.892 & 0.486 & 0.005 & 133.5 & -1.0 & 1 & MCA & 1998.666 & 0.505 & 0.010 & 127.1 & 0.1 & 1 & PIC \\
\hline 1987.754 & 0.487 & 0.005 & 133.4 & -0.6 & 1 & MCA & 2000.017 & 0.500 & 0.004 & 125.0 & -1.2 & 1 & WSI \\
\hline
\end{tabular}

\section{WDS $01213+1132-$ BU 4 AB - ADS 1097}

The previous orbit of Muller (1954) has a period which is too short and no longer represents the observations either in position angle or in separation. At the small separations BU $4 \mathrm{AB}$ is a difficult couple to observe because of the great difference in magnitude between the components. Our observation (1998.679 PIC) is the first speckle observation of this binary. The orbit is very eccentric and there are no observations near the perihelion between 1920 and 1945 when the components were at a distance of less than 0".15 (Fig. 2). Thus we have recalculated the orbital elements of BU 4 AB obtaining:

\begin{tabular}{|c|c|c|c|}
\hline node & $=$ & 147.0 & $(2000)$ \\
\hline omega & $=$ & 242.4 & \\
\hline i & $=$ & 133.1 & $A=0.02362$ \\
\hline e & $=$ & 0.868 & $B=-0.30558$ \\
\hline $\mathrm{T}$ & $=$ & 1943.069 & $F=-0.36809$ \\
\hline $\mathrm{P}$ & $=$ & 242.7 & $G=0.08730$ \\
\hline $\mathrm{n}$ & $=$ & 1.48331 & \\
\hline a & $=$ & 0.402 & \\
\hline
\end{tabular}


Our geometrical elements do not differ much from those found in 1954 by Muller, but our orbit, of degree 3 , is however more eccentric and the period is longer. The Hipparcos parallax is 0".00616 \pm 0".00141, to which corresponds a sum of the masses of the system of $4.7 M_{\odot}$, in excess for a binary of spectral type F1III (but C.D.S. report F0), while the semi-major axis is 65.3 A.U..

Ephemerides

$\begin{array}{cccccc}1 & 2 & 3 & 1 & 2 & 3 \\ 2001.0 & 0.514 & 110.8 & 2006.0 & 0.528 & 109.3 \\ 2002.0 & 0.517 & 110.5 & 2007.0 & 0.530 & 109.0 \\ 2003.0 & 0.520 & 110.2 & 2008.0 & 0.533 & 108.7 \\ 2004.0 & 0.522 & 109.9 & 2009.0 & 0.535 & 108.4 \\ 2005.0 & 0.525 & 109.6 & 2010.0 & 0.537 & 108.1\end{array}$

\begin{tabular}{|c|c|c|c|c|c|c|c|c|c|c|c|c|c|}
\hline $0-C$ & & & & & & & $0-C$ & & & & & & \\
\hline 1 & 2 & 3 & 4 & 5 & 6 & 7 & 1 & 2 & 3 & 4 & 5 & 6 & 7 \\
\hline 1978.600 & 0.360 & -0.061 & 114.7 & -4.3 & 3 & WOR & 1987.800 & 0.450 & -0.016 & 115.0 & -0.2 & 3 & HEI \\
\hline 1978.850 & 0.470 & 0.047 & 118.1 & -0.8 & 3 & HEI & 1990.841 & 0.470 & -0.008 & 112.1 & -2.0 & 2 & PRI \\
\hline 1981.832 & 0.470 & 0.032 & 116.2 & -1.4 & 3 & WOR & 1991.250 & 0.511 & 0.031 & 114.0 & 0.1 & 1 & HIP \\
\hline 1984.860 & 0.530 & 0.077 & 118.1 & 1.8 & 3 & HEI & 1991.970 & 0.480 & -0.003 & 114.5 & 0.8 & 2 & HEI \\
\hline 1985.810 & 0.390 & -0.067 & 111.4 & -4.5 & 3 & LBU & 1994.900 & 0.560 & 0.066 & 110.6 & -2.1 & 2 & HEI \\
\hline 1986.818 & 0.470 & 0.008 & 110.9 & -4.7 & 5 & SCA & 1997.679 & 0.490 & -0.013 & 113.1 & 1.3 & 1 & LIN \\
\hline 1986.870 & 0.490 & 0.028 & 115.5 & -0.0 & 3 & LIN & 1998.679 & 0.544 & 0.038 & 111.7 & 0.2 & 1 & PIC \\
\hline
\end{tabular}

\section{WDS $01551+2847-$ STF 183 AB - ADS 1522}

The binary star has been well observed. The orbits of Couteau (1973) and Starikova (1982) do not represent recent observations. The observations made before 1950 appear very scattered both in separation and position angle perhaps because of the considerable difference in magnitude between the components. Some perplexity is caused by the most recent observation available (1999.736 WSI) using speckle interferometry, because it leaves a strangely large residual in position angle.

$\begin{array}{llclll}\text { node } & = & 174.0 & +/- & 1.2 & \text { (2000) } \\ \text { omega } & = & 304.9 & " & 5.5 & \\ \mathrm{i} & = & 116.6 & " & 1.3 & \mathrm{~A}=-0.29155 \\ \mathrm{e} & = & 0.473 & " & 0.032 & \mathrm{~B}=-0.14660 \\ \mathrm{~T} & = & 1969.505 & " & 1.3 & \mathrm{~F}=-0.37866 \\ \mathrm{P} & = & 276.1 & " & 26.4 & \mathrm{G}=0.16344 \\ \mathrm{n} & = & 1.30388 & " & 0.12 & \end{array}$

Our orbit, of degree 3, has a shorter period and less eccentricity. The orbital elements are quite well defined, only the period is still rather uncertain (Fig. 3). The Hipparcos parallax is 0".00727 \pm 0 ".00189. The sum of the masses of the system, corresponding to such a measurement, is $3.8 M_{\odot}$, with an uncertainty of $82 \%$, in excess for a binary of spectral type F2, while the semi-major axis is 66.0 A.U.. The dynamical parallax is 0".0074, agreeing well with the observed one.

Ephemerides

$\begin{array}{cccccc}1 & 2 & 3 & 1 & 2 & 3 \\ & & & & & \\ 2001.0 & 0.319 & 153.8 & 2006.0 & 0.312 & 147.9 \\ 2002.0 & 0.318 & 152.7 & 2007.0 & 0.311 & 146.7 \\ 2003.0 & 0.317 & 151.5 & 2008.0 & 0.309 & 145.5 \\ 2004.0 & 0.315 & 150.3 & 2009.0 & 0.307 & 144.2 \\ 2005.0 & 0.314 & 149.1 & 2010.0 & 0.305 & 143.0\end{array}$


$\mathrm{D}-\mathrm{C}$

$\begin{array}{ccrrrrl}1 & 2 & 3 & 4 & 5 & 6 & 7 \\ 1978.840 & 0.240 & -0.020 & 188.2 & 5.8 & 3 & \text { HEI } \\ 1980.583 & 0.270 & -0.002 & 180.2 & 0.7 & 3 & \text { WOR } \\ 1980.860 & 0.240 & -0.034 & 180.8 & 1.7 & 3 & \text { HEI } \\ 1980.890 & 0.320 & 0.046 & 178.9 & -0.1 & 3 & \text { MRL } \\ 1980.904 & 0.257 & -0.017 & 178.4 & -0.6 & 1 & \text { TOK } \\ 1982.681 & 0.291 & 0.006 & 177.5 & 1.2 & 1 & \text { FU } \\ 1982.710 & 0.230 & -0.055 & 180.0 & 3.7 & 3 & \text { HEI } \\ 1982.859 & 0.279 & -0.007 & 174.1 & -1.9 & 3 & \text { TOK } \\ 1982.860 & 0.310 & 0.024 & 177.5 & 1.5 & 3 & \text { COU } \\ 1983.014 & 0.288 & 0.001 & 177.2 & 1.4 & 1 & \text { FU } \\ 1983.066 & 0.275 & -0.012 & 176.5 & 0.8 & 1 & \text { MCA } \\ 1983.713 & 0.287 & -0.004 & 175.2 & 0.4 & 1 & \text { MCA } \\ 1983.842 & 0.370 & 0.079 & 172.4 & -2.1 & 1 & \text { ZUL } \\ 1984.705 & 0.292 & -0.003 & 173.4 & 0.0 & 1 & \text { MCA } \\ 1984.900 & 0.280 & -0.016 & 174.8 & 1.7 & 2 & \text { HEI } \\ 1985.745 & 0.313 & 0.013 & 171.9 & -0.7 & 1 & \text { TOK } \\ 1985.770 & 0.340 & 0.040 & 171.2 & -0.7 & 1 & \text { COU } \\ 1985.810 & 0.270 & -0.030 & 171.1 & -0.8 & 2 & \text { LBU } \\ 1985.838 & 0.299 & -0.001 & 171.6 & -0.2 & 1 & \text { MCA } \\ 1986.800 & 0.270 & -0.034 & 170.8 & 0.2 & 3 & \text { HEI }\end{array}$

$\mathrm{O}-\mathrm{C}$

\begin{tabular}{|c|c|c|c|c|c|}
\hline 1 & 2 & 3 & 4 & 5 & 6 \\
\hline 1986.889 & 0.303 & -0.001 & 170.3 & -0.2 & 1 \\
\hline 1986.903 & 0.280 & -0.024 & 169.5 & -1.0 & 3 \\
\hline 1987.757 & 0.306 & -0.001 & 169.0 & -0.4 & 1 \\
\hline 1987.980 & 0.340 & 0.032 & 165.7 & -3.4 & 2 \\
\hline 1988.658 & 0.310 & 0.000 & 168.1 & -0.2 & 1 \\
\hline 1988.804 & 0.370 & 0.060 & 168.0 & -0.1 & 1 \\
\hline 1988.840 & 0.310 & -0.000 & 168.6 & 0.6 & 3 \\
\hline 1988.964 & 0.280 & -0.031 & 164.5 & -3.4 & 3 \\
\hline 1989.712 & 0.315 & 0.002 & 166.8 & -0.2 & 1 \\
\hline 1990.755 & 0.314 & -0.001 & 165.9 & 0.2 & 1 \\
\hline 1990.832 & 0.330 & 0.015 & 165.9 & 0.3 & 2 \\
\hline 1991.250 & 0.310 & -0.006 & 165.0 & -0.1 & 1 \\
\hline 1991.894 & 0.320 & 0.003 & 164.5 & 0.1 & 1 \\
\hline 1992.693 & 0.190 & -0.121 & 161.0 & -2.4 & 1 \\
\hline 1995.760 & 0.322 & 0.002 & 160.2 & 0.3 & 1 \\
\hline 1995.916 & 0.324 & 0.004 & 159.4 & -0.3 & 1 \\
\hline 1997.685 & 0.340 & 0.002 & 160.8 & 3.1 & 2 \\
\hline 1998.679 & 0.329 & 0.009 & 156.6 & 0.1 & 1 \\
\hline 1999.736 & 0.360 & 0.040 & 149.7 & -5.6 & 1 \\
\hline
\end{tabular}

\section{WDS $02182+3920-$ A $207-$ ADS 1762}

The orbit of Heintz (1975) no longer represents observations and the most recent one of Scardia (1982), although still acceptable, is based on visual observations which stopped in 1976. Our observation (1998.679 PIC), carried out at Pic du Midi with the B. Lyot telescope, is the first speckle observation of this binary. The measurement taken in 1991.25 by the satellite Hipparcos appears to be in disagreement with the observations made from the ground in the same years.

$\begin{array}{llcccl}\text { node } & = & 156.8 & +/- & 7.7 & (2000) \\ \text { omega } & = & 56.6 & " & 19.7 & \\ \mathrm{i} & = & 43.8 & " & 12.5 & \mathrm{~A}=-0.23044 \\ \mathrm{e} & = & 0.327 & " & 0.17 & \mathrm{~B}=-0.10446 \\ \mathrm{~T} & = & 1933.752 & " & 5.2 & \mathrm{~F}=0.18935 \\ \mathrm{P} & = & 193.3 & " & 68.2 & \mathrm{G}=-0.21516 \\ \mathrm{n} & = & 1.86239 & " & 0.66 & \end{array}$

Our orbit is preliminary because all the orbital elements are still rather uncertain (Fig. 4). The measurement of the parallax taken by the satellite Hipparcos is 0".01200 \pm 0 " 00311 ; it seems to be overestimated and leads to a sum of the masses of the system of $0.46 M_{\odot}$, which is frankly unacceptable for a system of spectral type F5. In 1981 Scardia, on the basis of a spectrum taken at Merate with the telescope Ruths, having a diameter of $137 \mathrm{~cm}$, and a spectrograph Boller and Chivens mod. 31523 (dispersion $114 \AA / \mathrm{mm}$ ), classified this star as being of spectral type F9 (Scardia, 1982). The dynamical parallax is 0".0065; the corresponding sum of the masses of the system is $2.87 M_{\odot}$.

Ephemerides

$\begin{array}{lccccc}1 & 2 & 3 & 1 & 2 & 3 \\ 2001.0 & 0.367 & 356.1 & 2006.0 & 0.367 & 0.7 \\ 2002.0 & 0.367 & 357.0 & 2007.0 & 0.366 & 1.6 \\ 2003.0 & 0.367 & 357.9 & 2008.0 & 0.366 & 2.5 \\ 2004.0 & 0.367 & 358.8 & 2009.0 & 0.365 & 3.4 \\ 2005.0 & 0.367 & 359.8 & 2010.0 & 0.365 & 4.3\end{array}$

$\mathrm{O}-\mathrm{C}$

$0-\mathrm{C}$

$\begin{array}{ccrcrcc}1 & 2 & 3 & 4 & 5 & 6 & 7 \\ 1988.850 & 0.280 & -0.076 & 349.8 & 5.0 & 3 & \text { HEI } \\ 1991.250 & 0.474 & 0.114 & 342.0 & -5.1 & 1 & \text { HIP } \\ 1996.000 & 0.350 & -0.015 & 356.3 & 4.8 & 2 & \text { HEI } \\ 1998.679 & 0.317 & -0.049 & 354.8 & 0.8 & 1 & \text { PIC }\end{array}$




\section{WDS $02407+2637-$ STT 43 - ADS 2034}

Heintz's orbit (1962) has not represented observations in separation for a long time. For that reason we recalculated a new set of orbital elements having a substantially shorter period. Although this star lends itself well to observation with speckle interferometry (the magnitudes of the components are 7.55 and 8.77) up to now there have been only three observations made with this technique and they have been concentrated within the last 5 years. The observations are quite numerous, but very scattered in separation.

\begin{tabular}{|c|c|c|c|}
\hline node & $=$ & 39.0 & $(2000)$ \\
\hline omega & $=$ & 203.8 & \\
\hline i & $=$ & 124.2 & $A=-0.75647$ \\
\hline e & $=$ & 0.324 & $B=-0.35398$ \\
\hline $\mathrm{T}$ & $=$ & 1804.422 & $F=-0.00889$ \\
\hline $\mathrm{P}$ & $=$ & 289.2 & $G=0.57912$ \\
\hline $\mathrm{n}$ & $=$ & 1.24481 & \\
\hline $\mathrm{a}$ & $=$ & 0.886 & \\
\hline
\end{tabular}

Our orbit must be considered as being preliminary (degree 4) because the arc of the observed orbit is only $90^{\circ}$ and is placed completely around the aphelion (Fig. 5). The parallax measured by Hipparcos is 0 ". $01385 \pm$ 0".00125. The corresponding total mass of the system is $3.1 M_{\odot}$, overestimated for a star of spectral type F7V, while the semi-major axis is 64.0 A.U. long. The dynamical parallax is 0".0149 agreeing well with the measured one.

Ephemerides

$\begin{array}{lccccc}1 & 2 & 3 & 1 & 2 & 3 \\ 2001.0 & 0.739 & 353.7 & 2006.0 & 0.693 & 348.6 \\ 2002.0 & 0.729 & 352.7 & 2007.0 & 0.684 & 347.5 \\ 2003.0 & 0.720 & 351.7 & 2008.0 & 0.675 & 346.4 \\ 2004.0 & 0.711 & 350.7 & 2009.0 & 0.667 & 345.2 \\ 2005.0 & 0.702 & 349.7 & 2010.0 & 0.658 & 344.1\end{array}$

$0-\mathrm{C}$

$\begin{array}{cccrrcc}1 & 2 & 3 & 4 & 5 & 6 & 7 \\ 1979.750 & 0.950 & 0.027 & 8.9 & -0.9 & 3 & \text { ZUL } \\ 1980.900 & 0.750 & -0.164 & 9.1 & 0.0 & 1 & \text { ZUL } \\ 1980.900 & 0.880 & -0.034 & 10.6 & 1.5 & 1 & \text { POP } \\ 1981.900 & 1.020 & 0.114 & 4.7 & -3.8 & 3 & \text { HEI } \\ 1982.796 & 1.070 & 0.171 & 9.0 & 1.1 & 4 & \text { LEF } \\ 1984.000 & 1.090 & 0.201 & 8.1 & 1.0 & 3 & \text { LBU } \\ 1986.245 & 0.860 & -0.010 & 4.7 & -0.9 & 2 & \text { ZUL } \\ 1986.760 & 1.000 & 0.135 & 6.3 & 1.0 & 3 & \text { LIN } \\ 1986.875 & 0.930 & 0.066 & 5.3 & 0.1 & 2 & \text { ZUL }\end{array}$

\begin{tabular}{ccccrcc} 
O-C & \multicolumn{1}{c}{$\begin{array}{l}\text { 3 } \\
1\end{array}$} & \multicolumn{1}{c}{4} & & 5 & 6 & 5 \\
& & & & & & \\
1990.074 & 0.830 & -0.007 & 3.6 & 0.8 & 4 & WOR \\
1990.940 & 0.950 & 0.121 & 2.4 & 0.2 & 2 & HEI \\
1991.250 & 0.863 & 0.037 & 3.9 & 2.0 & 1 & HIP \\
1995.770 & 0.790 & 0.004 & 355.2 & -3.1 & 1 & WSI \\
1995.970 & 0.880 & 0.096 & 358.3 & 0.1 & 2 & ALZ \\
1996.960 & 1.070 & 0.295 & 355.6 & -1.7 & 2 & ALZ \\
1998.679 & 0.754 & -0.006 & 354.9 & -0.9 & 1 & PIC \\
1999.689 & 0.680 & -0.070 & 357.8 & 2.9 & 1 & WSI \\
1999.709 & 0.736 & -0.014 & 354.9 & 0.0 & 1 & CAI
\end{tabular}

\section{WDS $02572+0153$ - A 2413 - ADS 2236}

The previous orbits of Scardia (1980) and Heintz (1991) by now leave systematic residuals on the observations both in position angle and in separation. We therefore recalculated the orbital elements obtaining:

$\begin{array}{lcccll}\text { node } & = & 4.6 & +/- & 0.7 & \text { (2000) } \\ \text { omega } & = & 274.5 & " & 3.4 & \\ \mathrm{i} & = & 69.7 & " & 1.1 & \mathrm{~A}=0.06516 \\ \mathrm{e} & = & 0.4593 & " & 0.014 & \mathrm{~B}=-0.20815 \\ \mathrm{~T} & = & 1929.241 & " & 0.44 & \mathrm{~F}=0.60979 \\ \mathrm{P} & = & 115.8 & " & 4.5 & \mathrm{G}=0.06586 \\ \mathrm{n} & = & 3.10880 & " & 0.12 & \end{array}$

This orbit, of degree 3, is by now well defined and will certainly change very little in the future. Only the period is still slightly uncertain. The parallax measured by Hipparcos is 0".02012 \pm 0".00150. The sum of the 
masses of the system, corresponding to such a value, is $2.1 M_{\odot}$, with an uncertainty of $29 \%$, agreeing very well with the values foreseen for a system of spectral type G0. The semi-major axis is 30.6 A.U.. Compared to the orbit calculated by Scardia in 1980, the total mass of the system, whose uncertainty was then of $55 \%$, is now much better defined. The dynamical parallax is 0".0193, well in agreement with the measured parallax (Fig. 6).

Ephemerides

\begin{tabular}{|c|c|c|c|c|c|c|c|c|c|c|c|c|c|}
\hline 1 & 2 & 3 & 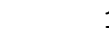 & & 2 & 3 & & & & & & & \\
\hline 2001.0 & 0.434 & 145.5 & 200 & & 0.486 & 154.1 & & & & & & & \\
\hline 2002.0 & 0.444 & 147.3 & $200^{\circ}$ & & 0.496 & 155.6 & & & & & & & \\
\hline 2003.0 & 0.455 & 149.1 & 200 & & 0.505 & 157.0 & & & & & & & \\
\hline 2004.0 & 0.465 & 150.8 & 200 & & 0.514 & 158.4 & & & & & & & \\
\hline 2005.0 & 0.476 & 152.5 & 201 & & 0.523 & 159.8 & & & & & & & \\
\hline $0-\mathrm{C}$ & & & & & & & $0-C$ & & & & & & \\
\hline 1 & 2 & 3 & 4 & 5 & 6 & 7 & 1 & 2 & 3 & 4 & 5 & 6 & 5 \\
\hline 1979.625 & 0.280 & -0.037 & 81.0 & 1.4 & 3 & WOR & 1989.090 & 0.290 & -0.038 & 113.5 & -0.6 & 1 & LBU \\
\hline 1979.840 & 0.320 & 0.004 & 80.8 & 0.5 & 3 & HEI & 1989.100 & 0.340 & 0.012 & 114.6 & 0.4 & 4 & WOR \\
\hline 1982.939 & 0.280 & -0.030 & 84.5 & -7.4 & 5 & MSS & 1990.916 & 0.341 & 0.002 & 121.2 & 1.1 & 1 & HRT \\
\hline 1983.960 & 0.340 & 0.029 & 94.5 & -1.2 & 3 & HEI & 1990.920 & 0.310 & -0.029 & 128.5 & 8.4 & 3 & HEI \\
\hline 1984.079 & 0.300 & -0.011 & 92.5 & -3.6 & 1 & SCA & 1991.250 & 0.343 & 0.001 & 122.0 & 0.9 & 1 & HIP \\
\hline 1985.050 & 0.330 & 0.018 & 95.5 & -4.3 & 3 & $\mathrm{SCA}$ & 1991.713 & 0.344 & -0.001 & 122.9 & 0.3 & 1 & HRT \\
\hline 1985.940 & 0.330 & 0.016 & 103.7 & 0.6 & 3 & LBU & 1995.768 & 0.382 & 0.002 & 134.2 & 0.4 & 1 & HRT \\
\hline 1986.069 & 0.310 & -0.005 & 104.5 & 1.0 & 3 & WOR & 1995.921 & 0.381 & -0.001 & 133.3 & -0.9 & 1 & HRT \\
\hline 1986.824 & 0.330 & 0.013 & 100.0 & -6.3 & 4 & SCA & 1996.020 & 0.390 & 0.007 & 131.0 & -3.4 & 2 & ALZ \\
\hline 1987.859 & 0.350 & 0.029 & 106.1 & -3.8 & 5 & SCA & 1998.679 & 0.418 & 0.008 & 140.5 & -0.1 & 1 & PIC \\
\hline 1989.043 & 0.340 & 0.013 & 112.6 & -1.4 & 4 & SCA & & & & & & & \\
\hline
\end{tabular}

Acknowledgements. The authors wish to thank the Washington Naval Observatory for giving the lists of measurements of visual binaries.

\section{References}

Aristidi, E., Carbillet, M., Prieur, J.-L., Lopez, B., Bresson, Y.: 1997, Astron. Astrophys. Suppl. 126, 555

Aristidi, E., Prieur, J.-L., Scardia, M., Koechlin, L., Avila, R., Lopez, B., Rabbia, Y., Carbillet, M., Nisenson, P., Gezari, D.: 1999, Astron. Astrophys. Suppl. 134, 545

Baize, P.: 1958, J. Observateurs 41, 165

Couteau, P.: 1973, Astron. Astrophys. Suppl. 12, 127

Heintz, W.D.: 1962, Veröff. Sternw. München 5, 139

Heintz, W.D.: 1975, Astrophys. J. Suppl. 29, 331

Heintz, W.D.: 1991, Astrophys. J. Suppl. 90, 311

Muller, P. : 1954, J. Observateurs 37, 63

Scardia, M.: 1980, Astron. Nachr. 301, 241

Scardia, M.: 1982, Astron. Astrophys. Suppl. 47, 167

Scardia, M., Prieur, J.-L., Aristidi, E., Koechlin, L.: 2000a, Astron. Nachr. 321, 255

Scardia, M., Prieur, J.-L., Aristidi,E., Koechlin, L.: 2000b, apjs 131, 561

Straizys, V., Kuriliene, G.: 1981, Astrophys. Space Sci. 80, 353

Starikova, G.A.: 1982, Sov. Astron. Lett. 8, 166

Addresses of the authors:

M. Scardia, Osservatorio Astronomico di Brera, Via E. Bianchi 46, 22055 Merate, Italy

J.-L. Prieur, L. Koechlin, UMR 5572 d'Astrophysique, Observatoire Midi-Pyrénées - Centre National de la Recherche Scientifique

E. Aistidi, UMR 6525 Astrophysique, Université de Nice Sophia-Antipolis,- Centre National de la Recherche Scientifique, Parc Valrose, 06108 Nice Cedex 2, France 


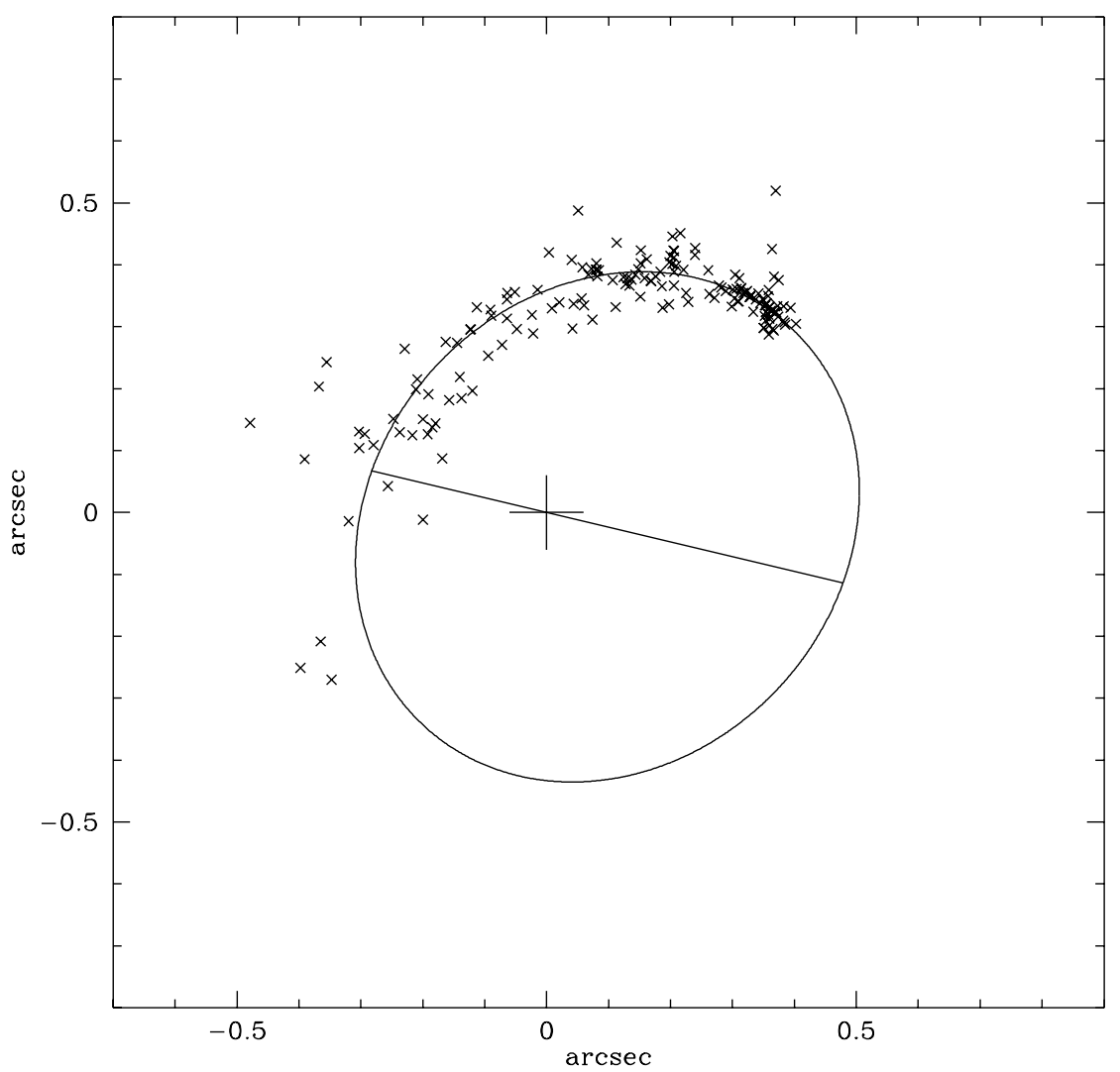

Fig. 1: STT 515 - ADS 940

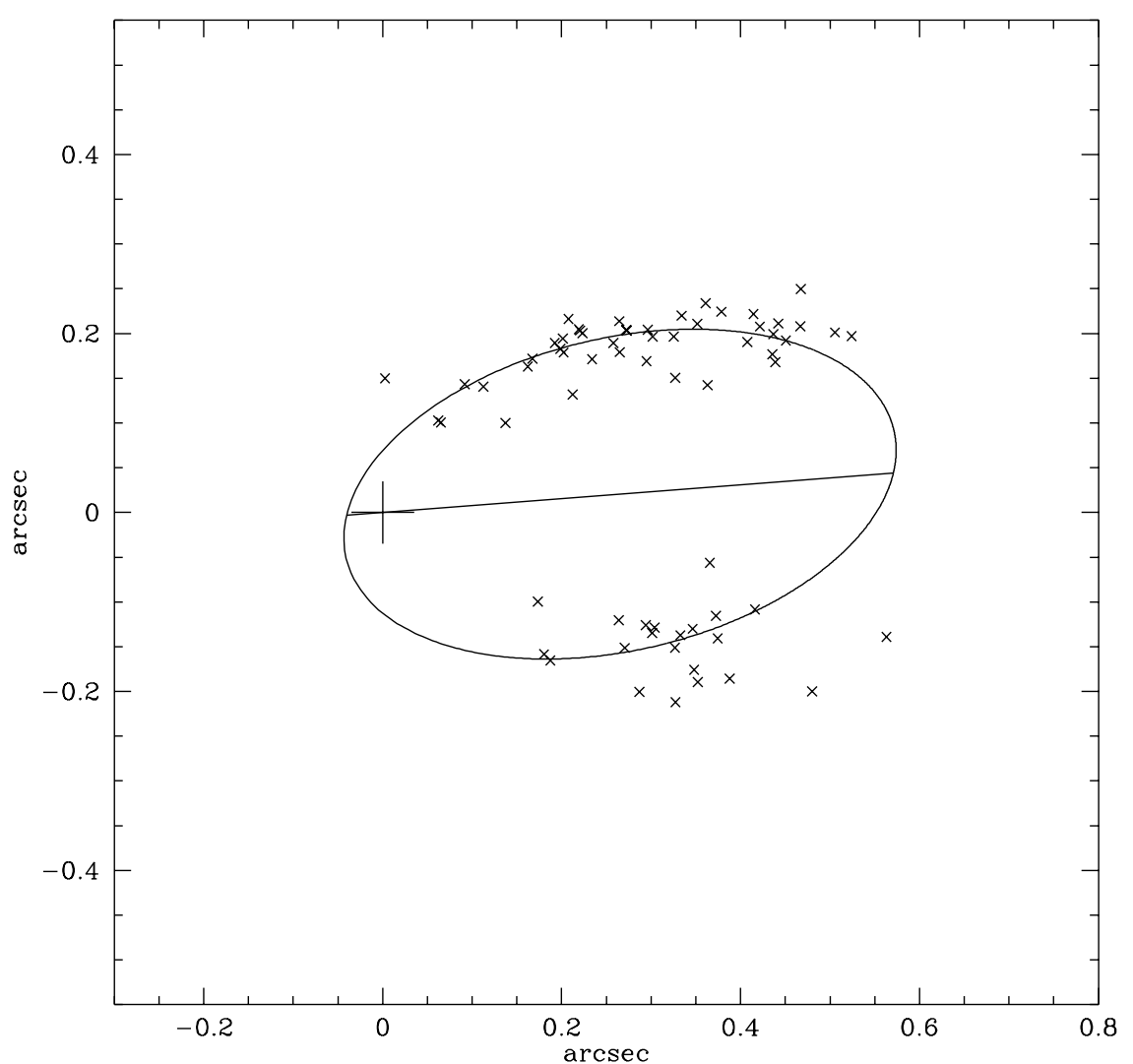

Fig. 2: $\mathrm{BU} 4 \mathrm{AB}$ - ADS 1097 


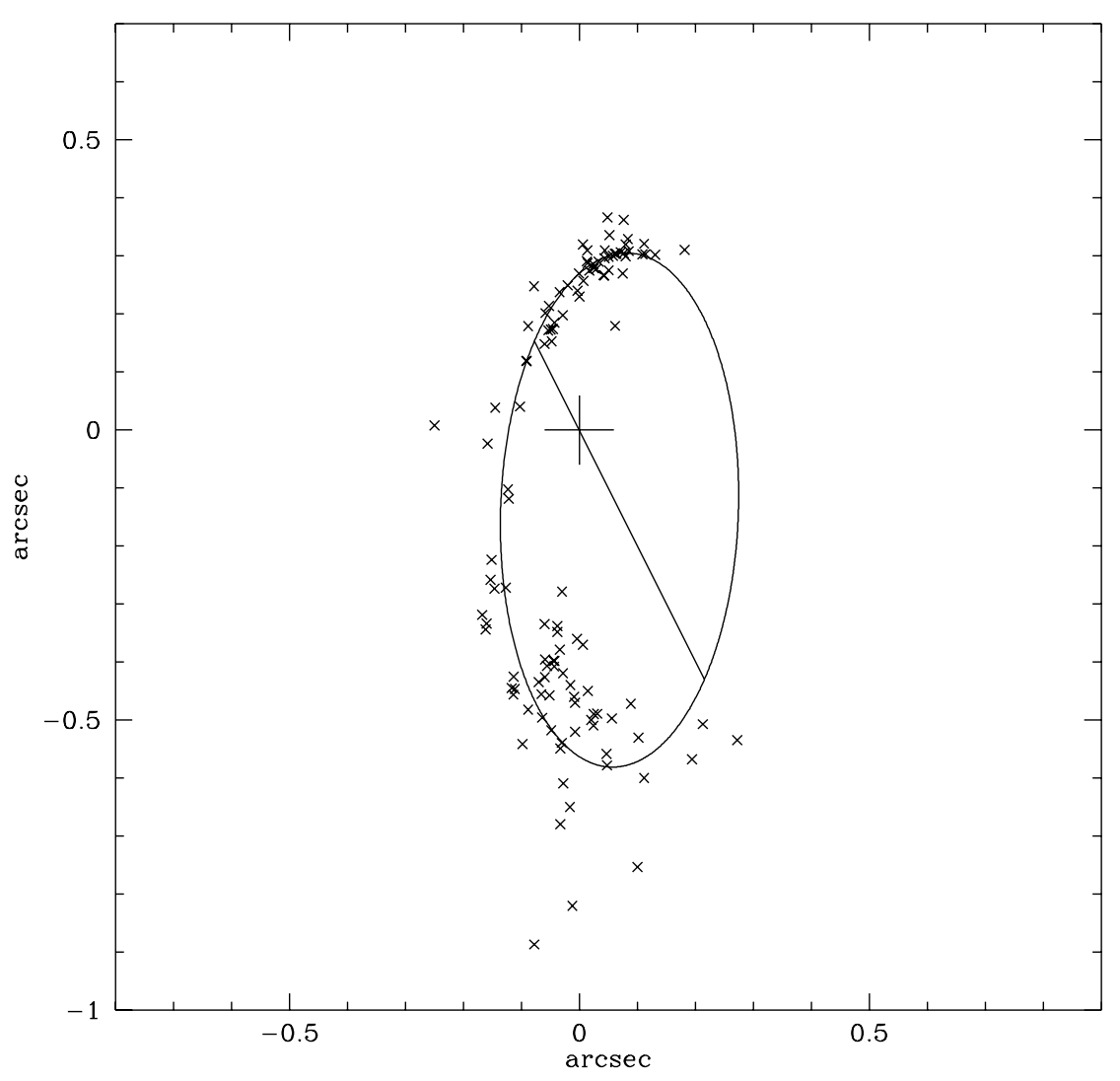

Fig. 3: STF 183 AB - ADS 1522

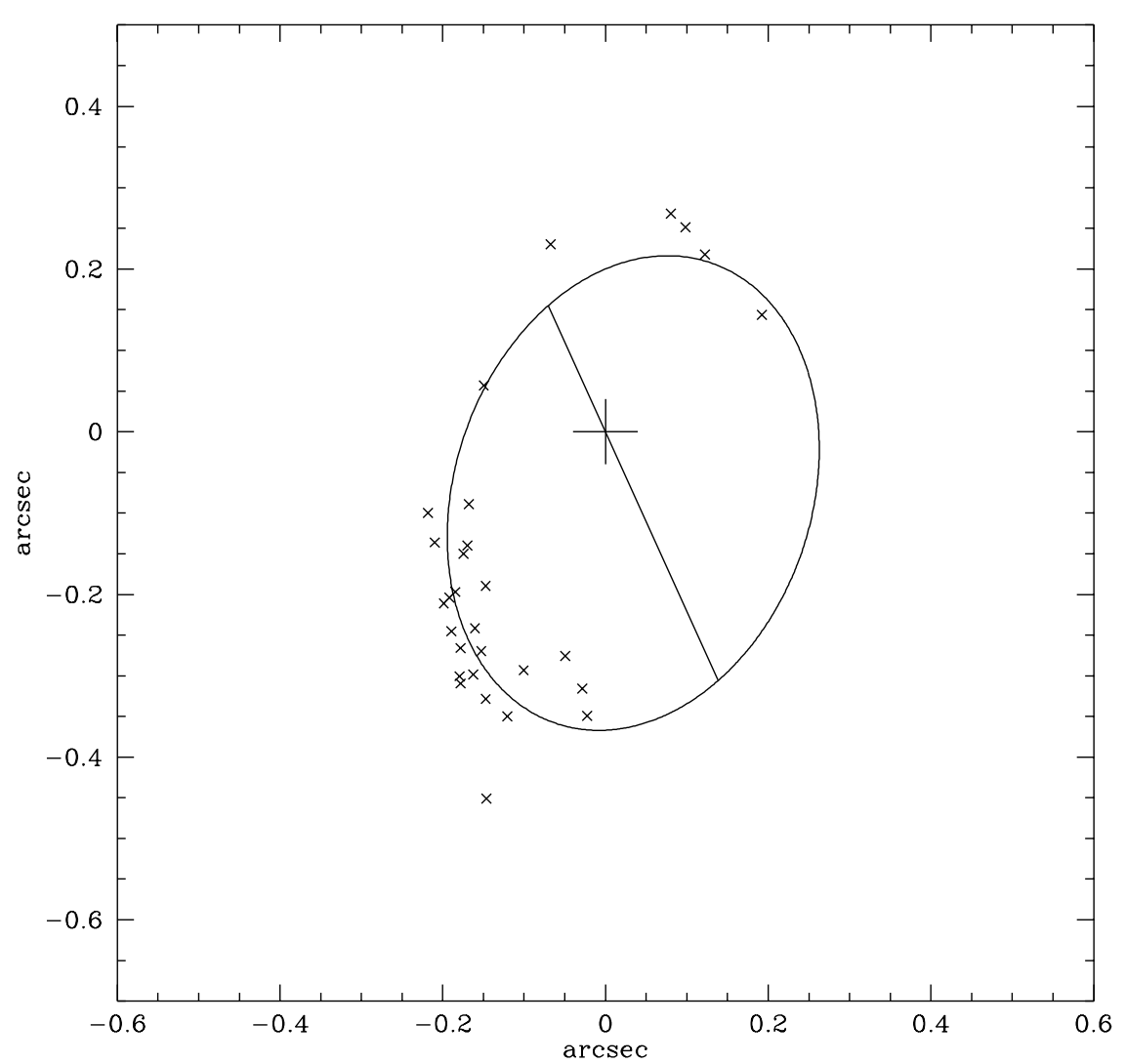

Fig. 4: A 207 - ADS 1762 


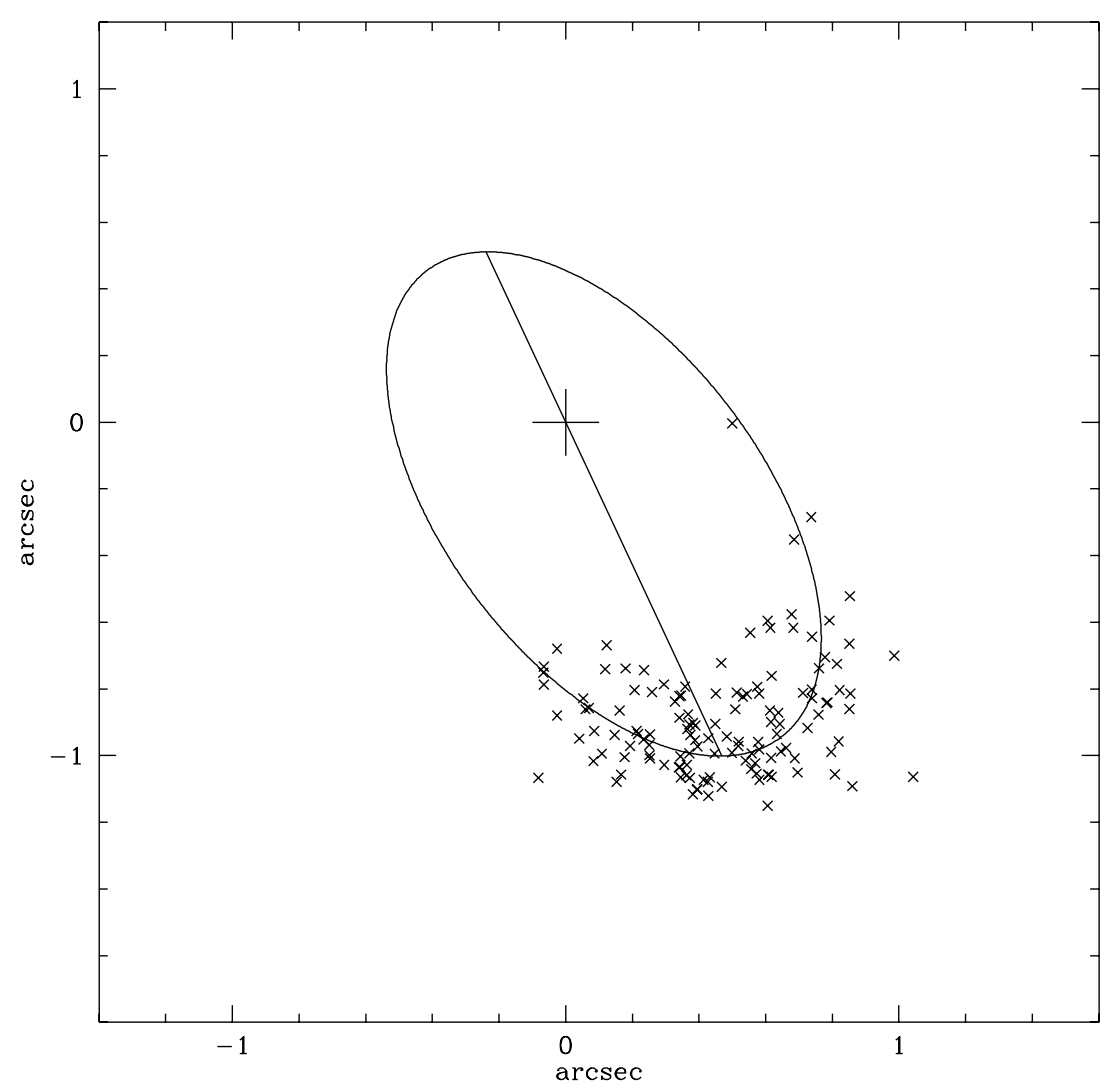

Fig. 5: STT 43 - ADS 2034

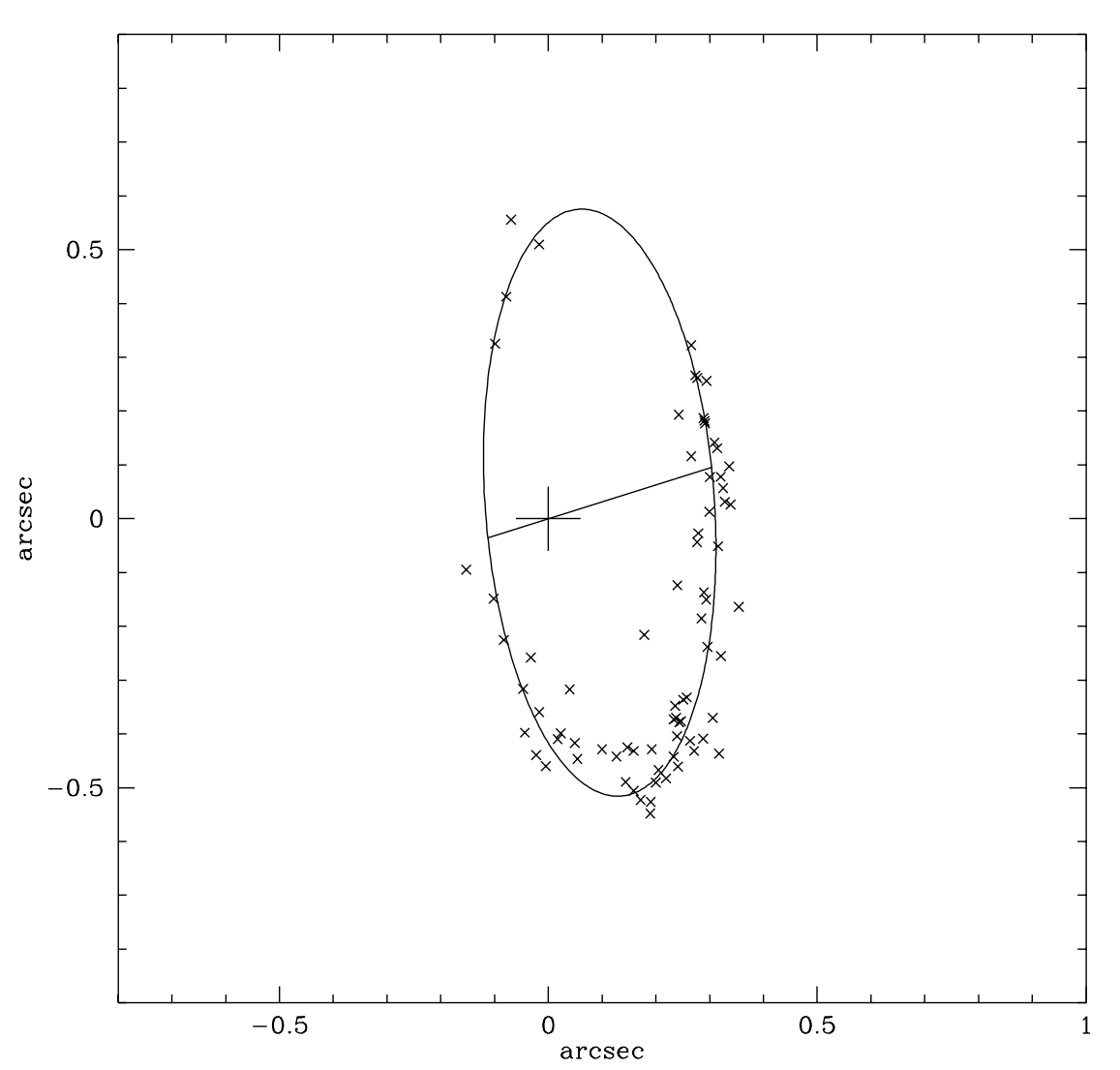

Fig. 6: A 2413 - ADS 2236 